\title{
La transhumancia y su incidencia en el poblamiento costero
}

Víctor Bustos S.*

Un conjunto de sitios arqueológicos, ubicados en la costa de la provincia de Antofagasta, de una u otra manera emparentados, son el motivo de la presente publicación. Básicamente, los podemos clasificar en dos grandes grupos, de acuerdo al análisis del material obtenido en cada uno de ellos.

a) Precerámicos.

b) Agroalfareros.

Los primeros los podemos subdividir a su vez en:

a) Conchales.

b) Campamentos con estructuras semicirculares.

El estudio de estos sitios intenta una aproximación a la problemática del poblamiento costero en la provincia de Antofagasta, la que es sólo posible en la medida que se puedan barajar algunas hipótesis de trabajo que no están claramente demostradas. En esta perspectiva se hace necesario plantear algunas dudas, como las siguientes:

1) Sospechamos la existencia en la costa de un poblamiento sumamente temprano: aun antes del óptimun climático. Es sugestivo que en los sitios más tempranos donde existen depósitos de basuras muy densos en su escala vertical y horizontal aparezcan desde sus primeros niveles, instrumentos de gran especialización, correspondiendo a un contexto económico de pesca y recolección (v.g., chuzos mariscadores, anzuelos de concha, arpones, etc.). Es probable, entonces, que debido a las variaciones de los niveles marinos (transgresiones) las posibles evidencias anteriores a las variaciones permanezcan sumergidas. De hecho, para la costa chilena se conoce la existencia de dos sitios bajo los actuales niveles marinos (La Herradura y Tongoy).

\footnotetext{
* Departamento de Antropología, Universidad del Norte, Antofagasta.
}

La dinámica de esta ocupación estaría dada por un desplazamiento horizontal.

2) La dieta alimenticia estaría incrementada en este primer caso por una actividad económica complementaria de caza y recolección terrestre, en las áreas adyacentes a los sitios ocupados; dependerá fundamentalmente de los recursos naturales que provea el medio ambiente y del conocimiento de él por parte de los primeros pobladores.

3) Por otro lado, existen sitios de escasa profundidad vertical en los depósitos de basuras, asociados directamente a estructuras semicirculares, conjunto que hemos llamado campamentos, entre cuyos restos materiales se destacan instrumentos especializados en actividades de caza (terrestre y marítima), lo que nos lleva a sospechar el establecimiento estacional de grupos preagrícolas desplazados desde el interior en los momentos que allí existían condiciones climáticas adversas (invierno boliviano), correspondiendo a prácticas transhumánticas.

4) Hemos encontrado sitios con cerámica en la terraza baja principalmente, lo que les da un carácter bastante tardío; por lo general se encuentran asociados a sitios con recursos de aguas más o menos permanentes (v.g., aguadas). Las evidencias señalan las influencias provenientes tanto del norte (San Miguel, Pocoma y Gentilar), como del interior (San Pedro Rojo-Violáceo) y del sur (diaguita).

Sospechamos, entonces, que las perspectivas de explotación de los recursos marítimos atraen a contingentes de individuos con conocimientos de agricultura, que se asientan en la costa durante temporadas más o menos prolongadas, realizando explotación marina a través de recolección, caza y pesca, y al mismo tiempo efectúan prácticas agrícolas en pequeña escala en las zonas adyacentes a los recursos de aguas y campamentos (v.g., La 
Chimba) probablemente como complemento a la dieta alimenticia.

La hipótesis que se maneja de transhumancia, para explicar la dinámica del poblamiento en la costa de la provincia de Antofagasta, es un tanto difícil de comprobar, no obstante, hay una serie de elementos que nos permiten sustentar dicha afirmación, que si bien es cierto no son definitorios, al menos aportan antecedentes a la hipótesis, la cual es susceptible de modificar a la luz de nuevas investigaciones.

Lo que nos llama la atención y nos conduce a serias sospechas de una práctica de transhumancia en la zona, se puede resumir brevemente como sigue:

1) La ausencia absoluta de elementos especializados para realizar actividades marítimas (recolección-pesca) aun en los niveles inferiores de aquellos sitios de poca profundidad de basuras, lo que nos lleva a suponer una actividad intensiva de recolección-caza, propia de grupos no especializados.

2) La presencia de ciertos elementos líticos en sitios costeros emparentados tipológicamente con industrias líticas del interior (v.g., Tambillo), aunque reconocemos la ineficacia de comparaciones tipológicas a grandes distancias, que por lo general conducen a apreciaciones erróneas por parte de los investigadores.

3) La presencia de ciertos artefactos (v.g., manos de moler, puntas lanceoladas, etc.) que corresponden principalmente a grupos cazadores recolectores, teniendo presente que son perfectamente aplicables en una economía marítima en un contexto de caza y recolección.

4) La presencia de semillas de algarrobo, tamarugo, chañar y lana de camélido, característica de grupos transhumánticos, aunque existe la posibilidad de haber sido introducidos en la zona, sin práctica de la transhumancia, ya sea por migraciones o por contactos culturales.

5) La existencia de una zona con evidencias fehacientes de transhumancia (v.g., Catl-42 y otros) emparentada con el interior a través de una serie de sitios a lo largo de las terrazas del río Loa (Núñez 1971), límite norte de la provincia de Antofagasta.

De lo anteriormente expuesto se desprende que:

1) Es necesario incrementar la investigación interdisciplinaria a lo largo de la costa de la provincia de Antofagasta, a fin de delimitar áreas-claves en el desarrollo costero.

2) El estudio de dichas áreas-claves y sus relaciones con otras áreas, a fin de obtener directrices y pautas concretas acerca de la dinámica del poblamiento costero.

3) El estudio integral de sitios de dichas áreas- claves, a fin de establecer tipologías, secuencias cronológicas y variantes en el desarrollo local.

4) Integrar el conocimiento de la dinámica costera a la de la provincia y ésta, a la del Norte Grande, considerándolo como un todo sólo dividible a manera operacional.

En esta perspectiva, el Departamento de Antropología de la Universidad del Norte, Sede Antofagasta, se ha planteado la urgente necesidad de un vasto plan de investigación siguiendo las líneas anteriormente expuestas a fin de abordar en forma integral la investigación arqueológica de la provincia y del Norte Grande. Plan que ya se está realizando en su etapa preliminar. 


\section{REFERENCIAS CITADAS}

NUÑEZ, L., 1971. "Secuencia y cambio en los asentamientos humanos de la desembocadura del río Loa". Boletín de la Universidad de Chile año XII, tomo II, N ${ }^{\circ} 112$. 